\title{
Integration of Arrival-Time Datasets for Consistent Quality Control: A Case Study of Amphibious Experiments along the Middle America Trench
}

\author{
by Melissa Moore-Driskell, ${ }^{*}$ Heather R. DeShon, ${ }^{\dagger}$ Wolfgang Rabbel, \\ Martin Thorwart, Yvonne Dzierma, and Ivonne G. Arroyo
}

\begin{abstract}
We have integrated waveform and arrival-onset data collected in Costa Rica as part of the National Science Foundation (NSF)-sponsored Costa Rica Seismogenic Zone Experiment (CRSEIZE) and along central Costa Rica and Nicaragua as part of the German SFB 574 program. The five arrays, composed of different sensor types (one- and three-component land and ocean bottom seismometers and hydrophones), were archived using different software packages (Antelope and SEISAN) and were automatically and manually picked using various quality criteria resulting in a disparate set of pick weights. We evaluate pick quality using automated arrival detection and picking algorithm based on the wavelet transform and Akaike information criterion picker. The consistency of the arrival information over various scales provides a basis for assigning a quality to the analyst pick. Approximately $31 \%$ of $P$ arrival times and $26 \%$ of $S$ times have been classified as high-quality picks (quality $0-1$ ). An additional $21 \%$ of $P$ times and $27 \%$ of $S$ arrivals are good quality (quality $2-3$ ). The revised quality picks are mapped directly into new pick weights for inversion studies. We explore the effect of new weighting and removal of poor data by relocating hypocenters through a minimum 1D velocity model and conducting double-difference local earthquake tomography (LET). Analysis of the hypocenter relocation and seismic velocity tomography results suggest that using the improved quality determinations have a greater effect on improving sharpness in the velocity images than on the magnitude of hypocentral movement.
\end{abstract}

Online Material: Figures of waveforms, event statistics, and tomography; and tables of station and event parameters, station qualities, velocity model, and hypocentral parameters.

\section{Introduction}

Imaging the Earth with ever increasing resolution using travel-time inversion techniques has become possible due to the increasing number and quality of seismic stations worldwide. Large-scale experiments such as USArray and expanding global and countrywide networks produce large travel-time datasets that can be integrated to obtain detailed images of Earth and its dynamic processes. Despite the sheer quantity and quality of the data currently being collected, resolution and uncertainty of inverse solutions are limited by the accuracy of individual arrival-time measurements.

*Also at University of North Alabama, Department of Physics and Earth Science, One Harrison Plaza, Florence, Alabama 35632.

Now at Southern Methodist University, PO Box 750395, Dallas, Texas 75275-0395.
For example, in seismic velocity tomography, calculated travel-time residuals are attributed to differences between the starting model used in the inversion problem and the actual Earth structure. Measured arrival-time errors are mapped into the observed travel times and thus lead to inaccurate residuals, resulting in noisy tomographic images. These errors commonly occur due to inconsistent handpicking because of noise, personal bias, or filtering (Diehl and Kissling, 2007).

Tomography accuracy does not solely depend on traveltime accuracy, but other factors such as model parameters, ray tracing, and inversion algorithms have largely been optimized in the past couple of decades through advances in forward modeling techniques and increased computing power (e.g., Thurber, 1983; Um and Thurber, 1987; Virieux et al., 

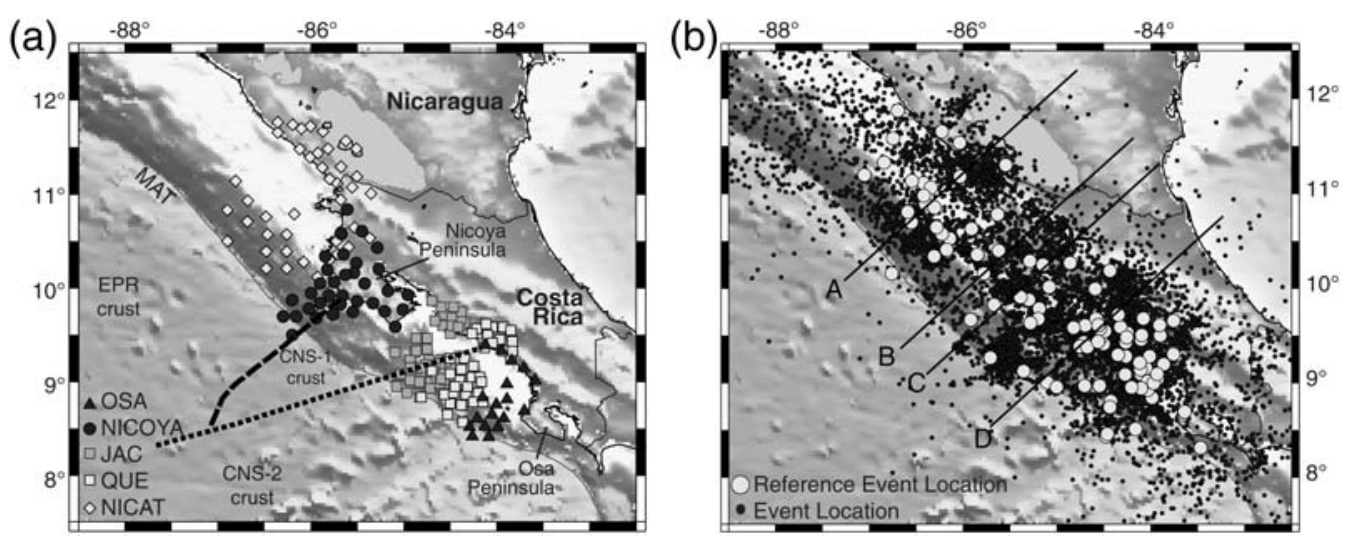

Figure 1. Nicaragua/Costa Rica study area along the Middle America subduction zone. (a) Station locations for the five arrays. Seismic stations for the OSA array are represented by the black triangles, NICOYA with black circles, QUE with white squares, NICAT with diamonds, and JAC with gray squares. The incoming plate shows significant variability along strike in plate age and origin (Barckhausen et al., 2001). (b) Black circles identify seismicity recorded during the CRSEIZE/SFB experiments. The reference events are shown as white circles. Cross sections that are discussed in the tomography section are shown by the black lines labeled A, B, C, and D.

1988; Podvin and Lecomte, 1991; Haslinger and Kissling, 2001; Husen and Kissling, 2001). Inconsistencies in the travel-time datasets remain a significant source of unmodeled error (Diehl et al., 2009; Husen et al., 2009). With larger and larger datasets becoming available, it becomes tedious, if not impossible, to personally review every arrival pick, especially when trying to integrate several datasets with each recording months to years worth of seismic data.

The complexity of seismic waveforms at local to regional distances can make the process of handpicking the major $P$ and $S$ arrivals difficult. Often the identification of phases is complicated by the close arrivals of many different phases at short hypocenter to station distances. Even a single seismologist will introduce their own subjectivity as to where they interpret the change of amplitude and change in primary frequency that denotes the arrival of the particular phase (Diehl and Kissling, 2007). Despite error, we assume, because of years of practice and the power of the human brain to analyze and interpret variability, that actual analyst picked arrivals are better than the alternative automatic picks. Though it has been shown that human and automatic picks are comparable (Sleeman and van Eck, 1999; Leonard, 2000; Zhang et al., 2003), typical automatic picking does not provide a tangible assessment of the actual quality of the automatic pick. Significant improvement in resolution and reliability of local to regional tomographic studies can be made by automatically repicking and weighting data (Di Stefano et al., 2006; Diehl et al., 2009), resulting in either adjusted picked onsets or increased accuracy differential times. Picking error can additionally be reduced using cross correlation (CC) of similar events (Got et al., 1994; Dodge et al., 1995; Shearer, 1997; Rubin et al., 1998; Waldhauser and Ellsworth, 2000; Rowe et al., 2002).

Considering the above, it would be desirable to combine the experience of a seismologist with the consistency of a computer algorithm to verify arrival onsets and prescribe a quality to the pick. Here we use an Akaike information cri- terion (AIC)-based automatic pick algorithm (Zhang et al., 2003) that utilizes wavelet transforms to quantify the quality of analyst identified (or original processing) arrival-onset times collected from five amphibious passive seismic experiments along the Middle America subduction zone. The goal is to compile the highest quality dataset of $P$ - and $S$-wave absolute and differential times for use in studies of the subduction seismogenic zone. The automated quality determination presented here results in more accurate and consistent weighting and identifies inaccurate analyst-determined phase onsets or errors in the original phase identification processing. In addition, $P$ - and $S$-wave differential times are calculated using CC with bispectrum verification (BCSEIS, Du et al., 2004) to further adjust differential times for more accurate data. The effect of the new weighting and removal of phases on hypocentral location is explored using relocation through a minimum $1 \mathrm{D}$ velocity model, which uses absolute data, and in double-difference local earthquake tomography (LET), which uses both absolute and differential data. The resulting high-quality integrated set of $P$ and $S$ absolute and differential times can be used for a wide range of studies, and the data preparation outlined below provides an automated approach to consistently quantify pick quality in large local earthquake datasets.

\section{Data}

The Nicaragua/Costa Rica segment of the Middle America subduction zone has been a focus site of seismogenic zone studies, in part because the Osa and Nicoya peninsulas extend close to the trench and because the region exhibits high along-strike variability in subduction characteristics (Fig. 1a). Previous studies of seismic velocity, attenuation, and earthquake location have shown that seismogenic zone behavior is strongly influenced by plate structure, temperature, and fluid-related processes (Hyndman and Wang, 1993; Protti et al., 1994, 1995, 2001; von Huene et al., 
1995; Hyndman et al., 1997; Barckhausen et al., 2001; Fisher et al., 2001; Currie et al., 2002; Harris and Wang, 2002; Newman et al., 2002; Bilek et al., 2003; DeShon and Schwartz, 2004; Ranero et al., 2005; Schwartz and DeShon, 2007; Rychert et al., 2008; Syracuse et al., 2008). LETderived velocity models aimed at characterizing lateral and downdip variability along the seismogenic zone have been limited to individual experiments (Fig. 1a). Five amphibious datasets were collected along the margin between 1999 and 2006, and each experiment used different sensors, database archive methods, automatic and manual onset identification techniques, and inconsistent quality determination. The ultimate goal is to combine available datasets for higher resolution studies that maintain consistency along strike.

\section{Costa Rica Seismogenic Zone Experiment}

The Costa Rica Seismogenic Zone Experiment (CRSEIZE) included a two-stage amphibious deployment that began in September 1999, jointly overseen by the University of California-Santa Cruz, the Observatorio Vulcanológico y Sismológico de Costa Rica (OVSICORI), and Scripps Institution of Oceanography (SIO) (Newman et al., 2002; DeShon et al., 2003, 2006; DeShon and Schwartz, 2004; Schwartz and DeShon, 2007). The passive seismic component combined three-component broadband and short-period seismic land arrays with three-component broadband ocean-bottom seismometers (OBS) (Fig. 1a; (E) Table S1, available in the electronic supplement); and recorded local, regional, and teleseismic events near the Osa and Nicoya peninsulas (Fig. 1b). The Osa deployment began mid-September 1999 and recorded two months of aftershocks from the 1999 $M_{\mathrm{w}} 6.9$ Quepos earthquake on 6 land seismometers and 14 OBS. In December 1999, these stations were redeployed on and near the Nicoya Peninsula and supplemented with 14 additional land seismometers.

All CRSEIZE land data were continuously recorded at $40 \mathrm{~Hz}$ and later processed into Standard for the Exchange of Earthquake Data (SEED) format. Waveform data are available through the Incorporated Research Institutions for Seismology (IRIS) Data Management Center (DMC). The OBS data were sampled at 64 or $128 \mathrm{~Hz}$. SIO processed these data into Seismic Analysis Code (SAC) format after applying timing corrections, identifying seafloor orientation using magnetic locking compasses (Sauter and Dorman, 1995), and calculating instrument response (see DeShon, 2004). Antelope software (see Data and Resources for details) was used to organize seismic waveforms, detect events (automatically and manually), generate initial locations, and compute local magnitudes $\left(M_{\mathrm{L}}\right)$. Phase onsets were detected using a short-term versus long-term average (STA/LTA) method implemented in the "dbdetect" function of the Antelope software. Phase associations and initial event locations were calculated using "dbgrassoc" (Antelope) through the global IASP91 velocity model (Kennett and Engdahl, 1991). Analysts then reviewed the automatic $P$ - and $S$-arrival picks,
Table 1

Initial Numbers of Events Detected for Each Original Dataset, the Numbers of $P$ and $S$ Arrivals for Each Dataset, and the Totals for the Integrated Dataset

\begin{tabular}{lrrr}
\hline Experiment & $\begin{array}{c}\text { Number of } \\
\text { Events }\end{array}$ & $\begin{array}{c}\text { Number of } P \\
\text { Arrivals }\end{array}$ & $\begin{array}{c}\text { Number of } S \\
\text { Arrivals }\end{array}$ \\
\hline OSA & 1479 & 10,834 & 9942 \\
NICOYA & 10,353 & 152,277 & 77,833 \\
QUE & 2158 & 18,501 & 4228 \\
NICAT & 1277 & 9408 & 7167 \\
JAC & 2693 & 31,076 & 7731 \\
Integrated & 17,960 & 222,096 & 106,901 \\
\hline
\end{tabular}

added thousands of additional $P$ and $S$ arrivals, and manually identified smaller events missed using automated techniques (DeShon, 2004; Ghosh et al., 2008). Earthquakes are shown in Figure $1 \mathrm{~b}$ and details of the dataset are in Table 1.

\section{SFB574 QUE, JAC, and NICAT Experiments}

The German SFB 574 project, operated by Christian Albrechts University of Kiel and former Leibniz Institute of Marine Sciences at the University of Kiel (IFM-GEOMAR), funded three amphibious experiments to study volatiles and fluid exchange along the erosional Nicaragua/Costa Rica margin. The experiments consisted of offshore OBS and oceanbottom hydrophones $(\mathrm{OBH})$ and temporary short-period land stations (Fig. 1a). The Jaco, Costa Rica (JAC) array recorded during 2002 (Arroyo et al., 2009) and was then moved south in 2003 to become the Quepos, Costa Rica (QUE) array (Dinc et al., 2010). Each array consisted of 23 offshore stations $(\sim 10$ three-component OBS and $\sim 13$ single-component $\mathrm{OBH})$ and 15 three-component short-period land stations. The Nicaragua amphibious array (NICAT) was deployed in December 2005 through June 2006 and consisted of 20 three-component OBS and 30 land stations (Dinc et al., 2011). During the NICAT and QUE experiments no more than 4-5 OBS were functioning. Only the hydrophone component worked during the JAC experiment. The JAC and NICAT arrays recorded at a sampling frequency of $100 \mathrm{~Hz}$, and the QUE array recorded at $50 \mathrm{~Hz}$. (E) Station information for the SFB arrays is given in Table S1 (available in the electronic supplement).

SFB574 seismic data were archived using SEISAN (Havskov and Ottemöller, 2005). An STA/LTA trigger was used to identify phase onsets. Locations were calculated using the program HYP (Lienert and Havskov, 1995). Initial earthquake locations are shown in Figure $1 \mathrm{~b}$ and arrival information in Table 1.

\section{Reference Events}

We selected a set of 20 reference events from each of the five experiments to represent a cross section of earthquake and station distribution. The reference events were used to choose appropriate parameters for the wavelet-AIC automatic picker and waveform cross correlation. These events were selected to span the spatial, temporal, and magnitude 
range; station coverage was also considered. Locations for the seismicity recorded during the experiments and the reference events are shown in Figure 1b. Reference event waveforms were visually inspected to grade initial overall quality and noise level and then again to verify the performance of the cross correlator and automatic picker.

\section{Quality Determination}

\section{Method}

Each of the five experiments in our study implemented a quality scheme to rate the confidence of each picked arrival. For example, originally JAC's phase picks were weighted from 0 to 4 , with 0 denoting the most confident pick with an uncertainty of $\pm 0.05 \mathrm{~s}$ and 4 for the most uncertain picks (>0.2 s; Arroyo et al., 2009). Data from the QUE and NICAT experiments were evaluated in a similar manner. However, quality for the CRSEIZE phase onsets was defined less consistently, and at times not at all, in part because Antelope by default does not provide a simple method to define quality using the standard 0-4 criteria. Herein lies the problem of the quality control obstacles of large seismic datasets. Tens of analysts were involved in processing the five datasets and handpicking $P$ and $S$ onsets. Certainty of a pick is highly subjective. As a result, there has been no standardized procedure for quantifying pick quality that can be used to properly weight data for inverse approaches. Thus we decided that integrating the five datasets required evaluation of the quality of each arrival pick using an automated and standardized measures.

Recent developments in wavelet-transform methods (Anant and Dowla, 1997; Zhang et al., 2003) and polarization (Vidale, 1986; Reading et al., 2001) have been used for phase detection, with the most popular method for seismologic studies being the autoregressive (AR) model (Yokota et al., 1981; Maeda, 1985; Takanami and Kitagawa, 1988; Leonard and Kennett, 1999; Sleeman and van Eck, 1999; Leonard, 2000). AR techniques are based on the understanding that a seismogram can be divided into segments that are locally stationary before and after the phase onsets, with the dividing point between the two distinct AR processes assumed to be the phase arrival (Sleeman and van Eck, 1999). Following Kitagawa and Akaike (1978), an adapted automatic picker based on the AIC can be used to evaluate how well the trial and error AR process fits. As the dividing point of the two stationary segments move, the location of the minimum AIC value is assumed to be the best location and thus the phase onset time (Akaike, 1973).

We use a wavelet-AIC automatic picker as implemented by Zhang et al. (2003) to ensure standardized quality measurements across all available datasets. A similar technique was developed by Diehl et al. (2009). The picker method of Diehl et al. (2009), however, uses a method by Maeda (1985) that calculates the AIC coefficients without the AR processes. Autoregressive AIC pickers are optimal if they are applied to the part of the signal that contains the onset in order to guarantee that the global minimum of the AIC function represents the $P$ or $S$ phases (Zhang et al., 2003). Because the AIC performs best when started around the onset, a wavelet transform application is initially used on the waveforms to detect potential phase onsets and to establish a window around the arrival for which the AIC picker will use to give a final arrival time (i.e., Takanami and Kitagawa, 1991; Leonard and Kennett, 1999; Sleeman and van Eck, 1999). Unlike the Fourier transform, the wavelet transform can represent the seismogram locally both in time and frequency domains with detail that matches the scale used. This transform calculates the time-dependent contributions to the waveform in terms of scale, making it nonredundant, unlike the spectrogram method that calculates the amplitudes of particular frequencies at particular times. The coarse features can be seen on large scale and fine features on small scales. The scale factor regulates the expansion or compression of the wavelet. Major features of the signal will remain visible over many scales, whereas characteristics such as noise will disappear at larger scales. Figure 2 shows examples of wavelet transforms for $P$ and $S$ waves in the dataset. The rapidly increasing wavelet coefficients mark the area of the phase onset. For our evaluation of arrival pick quality, we do not use the wavelet transform to pick the arrivals. Rather, we use it to provide a window around a suspected arrival for the AIC picker to evaluate. The onset of the arrival is the point at which the AIC has a minimum value (Fig. 2). Using this method there is no need to filter the data prior to the pick analysis. Additionally we do not use the automatic picks in further studies; we simply use the automatic picks to compare with the original picks as described below.

Onsets identified using the wavelet-AIC method are compared with the original picked arrival. The automatic pick is used to quantify the quality of the original pick. For example, if the automatic pick is within $\pm 0.05 \mathrm{~s}$ from the original picked time, the original pick is given a quality of 0 (most confident pick). We assign pick quality on a $0-5$ scale whose values are shown in Table 2, with quality 0 being the best picks, 4 being poor quality/confidence picks, and 5 denoting when the wavelet-AIC picker failed to detect a consistent pick across the different wavelet scales. Figure 3 shows examples of waveforms from the OSA experiment along with the originally picked onsets and wavelet-AIC picked onsets. (E) Examples from the other five experiments are documented in Figure S1 (available in the electronic supplement). The automated pick is used solely to assign a quality to the original pick. Because the majority of the phase picks were selected by a person or at least visually inspected, we choose to use the original pick if it is deemed high quality by the wavelet-AIC picker. We assume that an experienced analyst will produce higher quality picks than the automated method.

\section{Results}

A summary of the phase quality as determined by the wavelet-AIC picker scheme is given in Figure 4. Quality is 
(a)
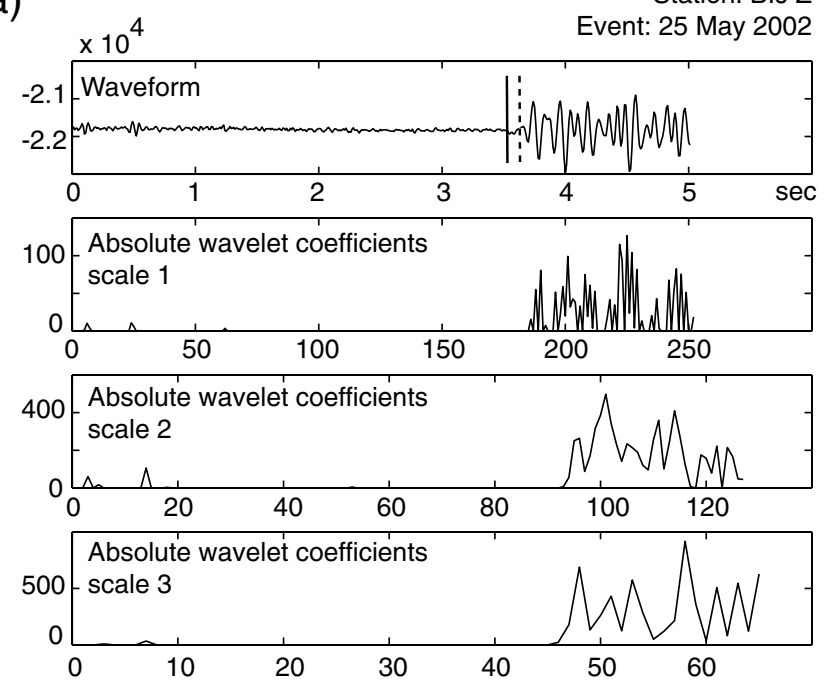

(b)
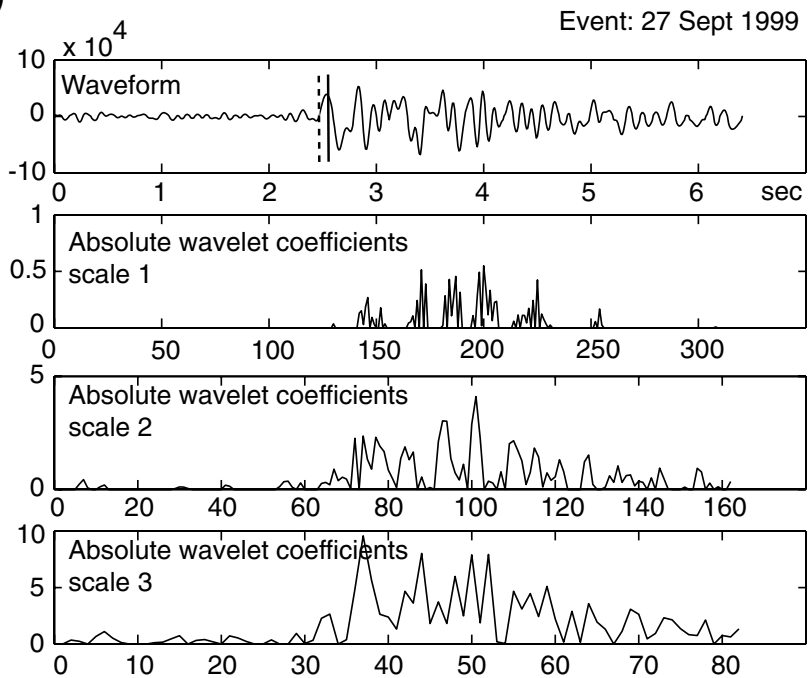

Array: OSA

Station: SS18 N Event: 27 Sept 1999
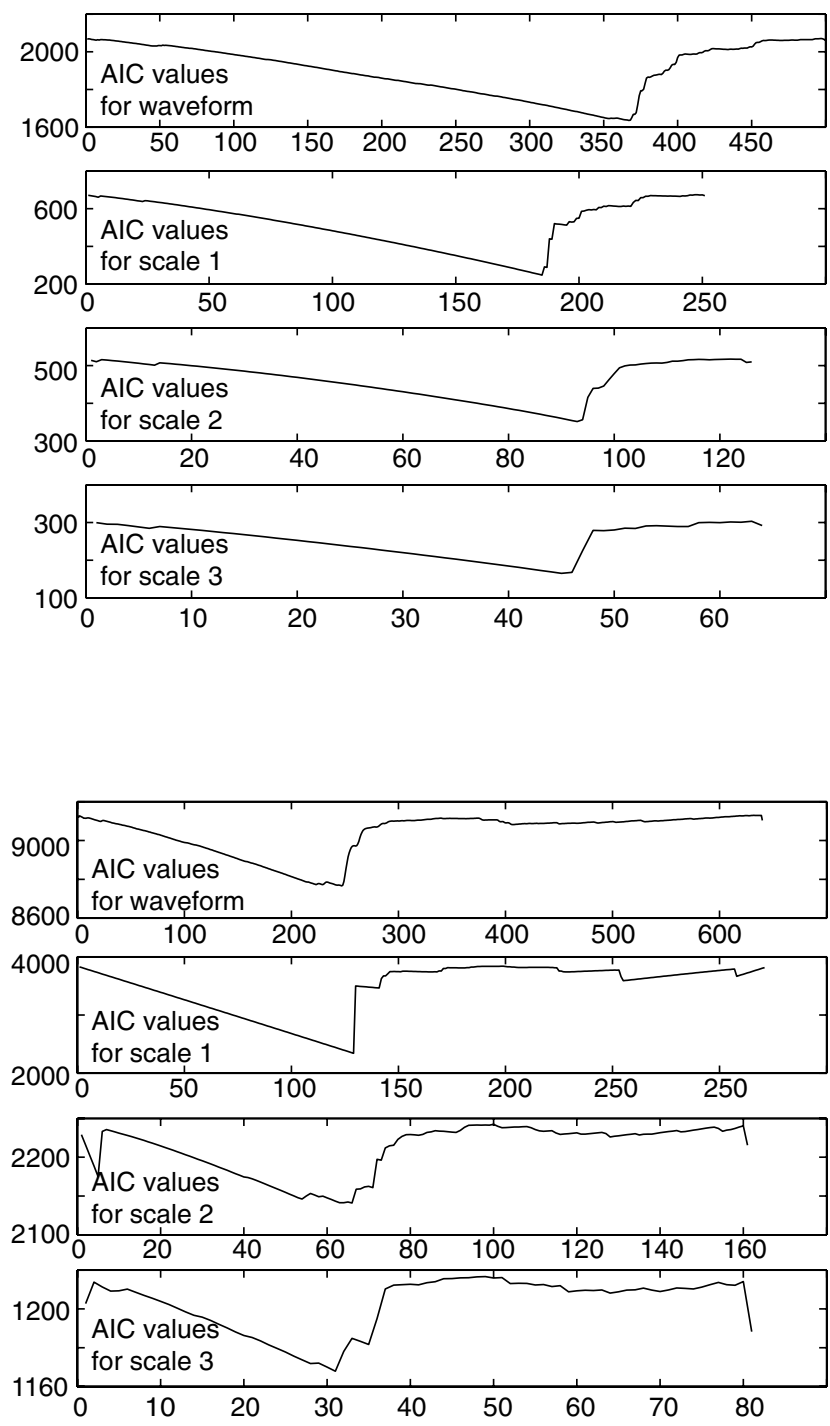

Figure 2. Waveform and absolute wavelet coefficients for three scales (left column) and their corresponding AIC values (right column). Analyst picks are shown by the vertical solid black line on the waveform. Wavelet-AIC picks are shown as the dashed line. (a) $P$ arrival for land station BIJ of the JAC array. The rapidly increasing coefficients mark the area of the wave onset, and this time window will be used to guide the AIC picker. The automatic pick differed from the handpick by 0.12 s. (b) $S$ arrival for OBS station SS18 of the OSA array. The automatic pick differed from the handpick by $0.079 \mathrm{~s}$.

broken down by experiment and further by reference events and land versus OBS stations. The first column under each experiment shows the $P$ - and $S$-pick quality for the complete dataset. Figure $4 \mathrm{f}$ shows the quality of the entire integrated dataset. Approximately $31 \%$ of all the $P$-arrival picks qualify as extremely confident/high-quality picks (quality $0-1$ ). Another $21 \%$ qualifies as good quality (quality 2-3). Results of the $S$ quality assessment yield $26 \%$ having excellent quality (0-1) and an additional $27 \%$ with good quality (2-3). We would not recommend that quality 4 picks (19\% for $P$ and $27 \%$ for $S$ ) be used in further research. Quality 5 represents the data with which the automatic picker failed to detect a consistent arrival onset at the different wavelet scales and thus would also be undesirable data for further use.

We find lower quality for the $S$ arrivals, which likely reflects the inability of the automatic pickers (and humans) to locate $S$ arrivals in $P$ coda and/or the increased complexity of the $S$ waveforms. Figure 5 shows two examples of typical $S$ picker failure. Figure 5a shows a waveform with a small precursor phase arriving before the actual $S$ phase. The picker does not work well in this scenario. The picker requires that at least three of the four AIC pick locations at the different wavelet scales (raw waveform, scale 1, scale 2, and scale 3; see 2) fall relatively close together $(<0.5 \mathrm{~s})$ to be considered a 
Table 2

Quality Determinations Assigned to Manual Catalog Picks and tomoDD Weighting

\begin{tabular}{ccc}
\hline Quality & $\Delta t^{*}(\mathrm{~s})$ & tomoDD Weight \\
\hline 0 & $0-0.05$ & 1 \\
1 & $0.051-0.1$ & 0.75 \\
2 & $0.11-0.3$ & 0.5 \\
3 & $0.31-0.5$ & 0.25 \\
4 & $>0.5$ & Not used \\
5 & Picker fails & Not used \\
\hline
\end{tabular}

*Absolute value of differential times $(\Delta t)$ in seconds between the original picked arrival and the wavelet-AIC pick.

confident phase pick. The precursory phase creates its own local AIC minimum therefore complicating the determination of the local minimum that corresponds to the actual $S$ phase. The example in Figure $5 b$ fails due to the emergent nature of the $S$ arrival. Again, the picks at different scales are not consistent enough to determine a phase arrival. In both cases, the human pick (solid vertical line on the raw waveforms) cannot be given a very high confidence level due to the complex nature of the waveforms.

With such a large dataset, we suggest that removing the possibly bad $P$ - and $S$-wave data as opposed to leaving data of unquantified quality will strengthen the integrated dataset described above. This hypothesis is tested further below. The reference events show a similar trend to the complete dataset. In all experiments, the land stations exhibit slightly higher quality than the OBS stations which is expected because ocean stations have greater noise sources.

We visually inspect every waveform in the reference events for all five experiments to ensure that the automatic picker was assigning a reasonable quality factor. For the OSA array, $9 P$ arrivals (out of 230 picks) and $19 S$ arrivals (out of 231 picks) were either incorrectly given a poor quality assessment (quality 4) or the picker failed to detect an arrival (quality 5 ) when visual inspection showed an obvious, clean phase arrival with an accurate analyst pick. The NICOYA reference dataset contained 26 (of 247) $P$ arrivals and 35 (of 166) $S$ arrivals that were good analyst picks but were given poor ratings. Analyzing the SFB experiments, QUE lost $8 P$ picks (out of 298 ) and $12 S$ picks (out of 85 ) due to automatic picker error. JAC had $30 \operatorname{good} P$ arrivals (230 total) and $29 \operatorname{good} S$ arrivals (104 total) that were given qualities 4 or 5 . In the NICAT database, 28 of $194 P$ picks and 26 of $135 S$ picks were lost to pick inaccuracy. Inspection revealed no obviously bad picks that were given good quality ratings. Additionally, (E) Table S2 (available in the electronic supplement) shows typical examples of how the new qualities compare to the original qualities.

\section{Waveform Cross Correlation}

Double-difference LET techniques reduce noise in resulting velocity images by inclusion of differential time
OSA 26 Sept 1999

$8.45^{\circ} \mathrm{N} 84.46^{\circ} \mathrm{W}$, Depth $31 \mathrm{~km}$, Magnitude 2.61
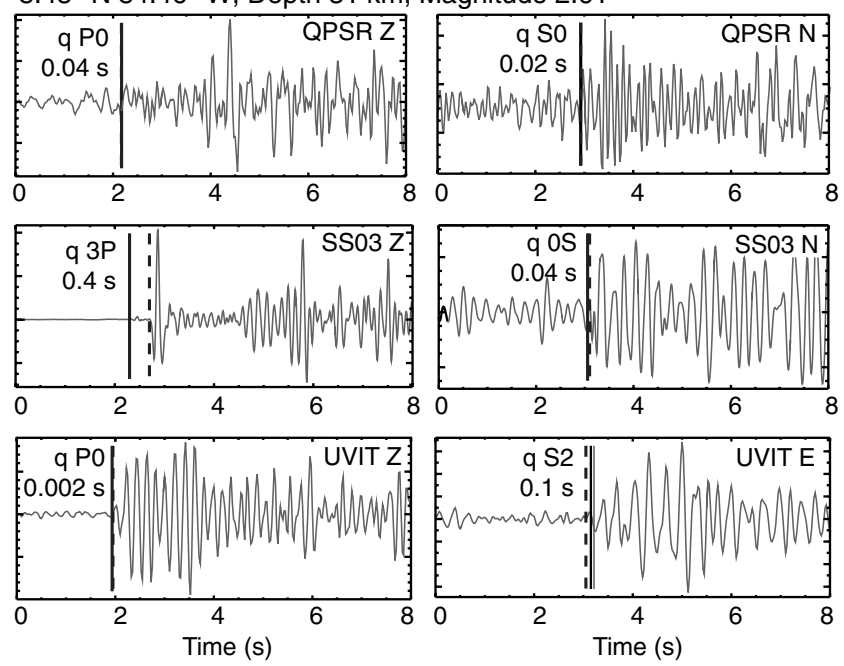

Figure 3. Example of waveforms from the OSA experiment with the handpicked arrivals (solid vertical lines) and the automatic picks from the wavelet-AIC automatic picker (dashed lines). Arrival phase $(P / S)$ and quality $(q)$ are indicated on the waveforms. Differential time between the analyst and automatic picks are shown below the quality in seconds. Station name and component are listed for each waveform. (E) Examples for the other four arrays are shown in Figure S1.

data. Differential times, the time difference between phases reported at common stations for pairs of earthquakes, can be calculated directly from catalog data or via CC (Waldhauser and Ellsworth, 2000; Zhang and Thurber, 2003). We will test the effect of improved quality control using double-difference techniques. We use the bispectrum cross correlation for seismic events package (BCSEIS; Du et al., 2004), which correlates waveforms in the spectral domain and directly computes differential times. CC is first performed between the Fourier transforms of the waveform data, which is also known as correlation in the second-order spectral domain. BCSEIS also calculates the bispectrum CC (BCC), equivalent to correlation in the third-order spectral domain, because this correlation is less sensitive to correlated noise such as wind or waves. The BCC is used to verify (accept or reject) the results from the standard frequency CC. Subsample precision is obtained through application of a coherence-weighted linear fitting of the cross-spectrum phase, a technique of Poupinet et al. (1984). Differential times (dt) are computed for event pairs of highly similar waveforms at one or more stations.

CC studies frequently use the correlation coefficient thresholds (i.e., 0.80) to accept or reject arrivals or differential times at a specific station or event pair. Such thresholds may, if too high, discard many accurate times, and if too low, contaminate the dataset with unreliable information. These problems are most often an issue when high noise levels are present, resulting in low CC coefficients. These low coefficients are interpreted as seemingly dissimilar waveforms. BCSEIS takes waveform similarity at all stations for a given event pair into account and uses a tiered set of thresholds to 
(a) OSA

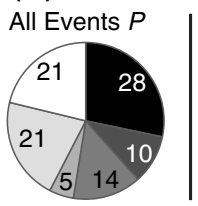

10834

All Events $S$

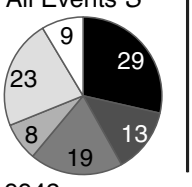

9942

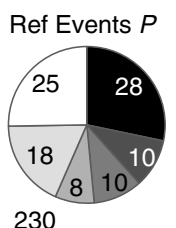

230

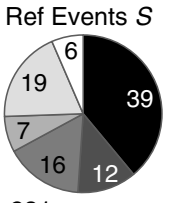

231

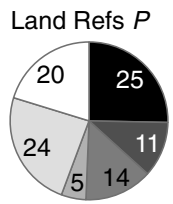

79

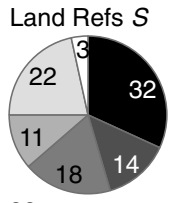

88

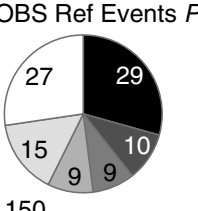

150

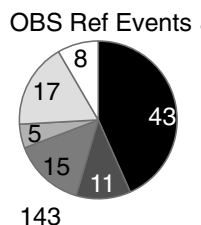

143

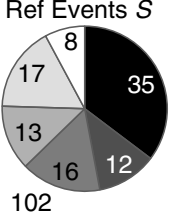

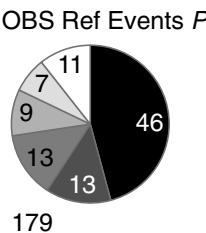

179

118

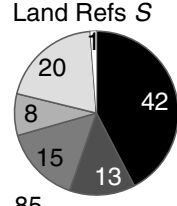

85

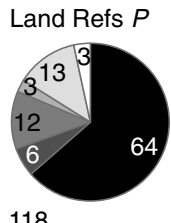

OBS Ref Events $S$

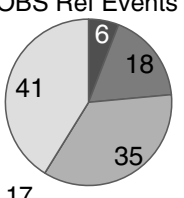

\section{(b) NICOYA}

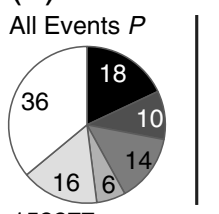

152277

All Events $S$

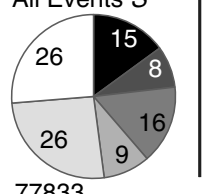

77833

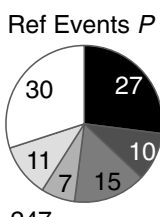

247

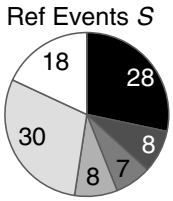

166

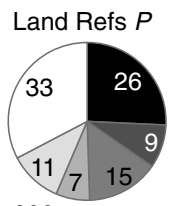

202

Land Refs $S$ OBS Ref Events $S$

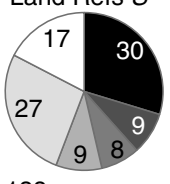

138

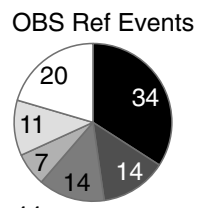

44

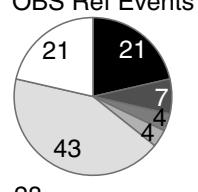

28 (d) NICAT

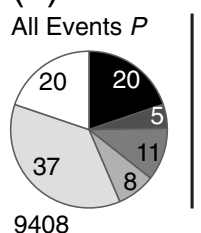

All Events $S$

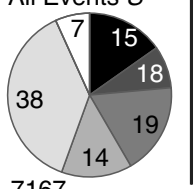

7167

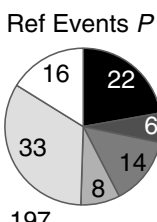

197

Ref Events $S$

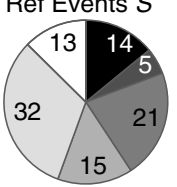

135

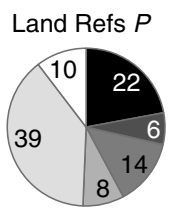

154

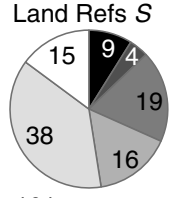

101
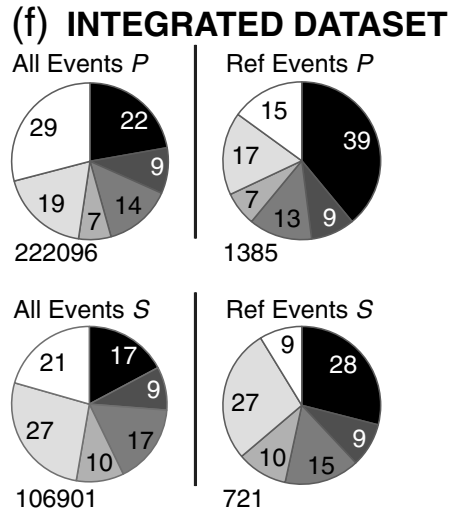

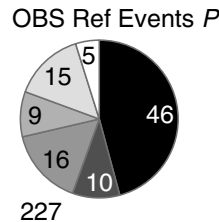

227

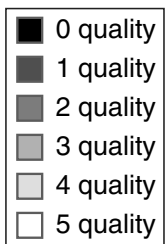

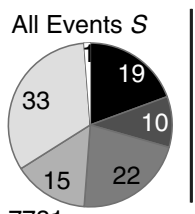

7731
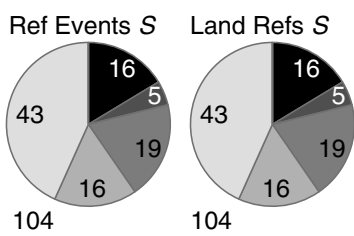

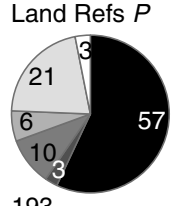

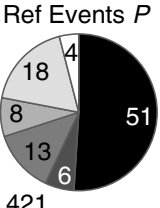

Figure 4. (a-e) Distribution statistics on the redetermined quality factors for all arrivals, separated by array. Labels indicate if $P$ or $S$ data are included in the pie chart. The total number of picks represented in each chart is indicated at the lower left of the chart. Reference events were chosen to be representative prior to any calculations, and their quality closely mimics that of the overall datasets for each array. Land stations yield slightly higher-quality onsets than OBS stations. (f) The quality of the integrated dataset.

reject or accept differential times for inclusion in a final dataset. For the Nicaragua and Costa Rica data, the initial CC is performed on band-pass filtered waveforms $(1-10 \mathrm{~Hz}, 2$ poles, 2 passes) while the BCC is calculated on both the raw and the filtered data. The original picks were always made on unfiltered data. The initial CC derived time delay is translated to a differential time if the initial $\mathrm{CC}$ and both BCC delays are within two samples of one another, a user-defined choice. All differential times associated with CC coefficients $\geq 0.65$ are kept, similar to a traditional threshold approach. If an event pair has a CC coefficient $\geq 0.80$ at any recording station, then data at other stations with coefficients $\geq 0.50$ are also included in the final dt dataset. Examples are shown in Figure 6. These thresholds were set after careful review of the reference dataset.

(E) Figure S2 (available in the electronic supplement) summarizes the CC results using a multithreshold approach with bispectrum verification for each of the five experiments, as well as results assuming a traditional single threshold of 0.80 and 0.65 . For the integrated dataset, CC resulted in 22,261 similar event pairs, 47,326 $P$ dts, and 24,980 $S$ dts. This is $\sim 2$ times more event pairs than traditional single 
(a)
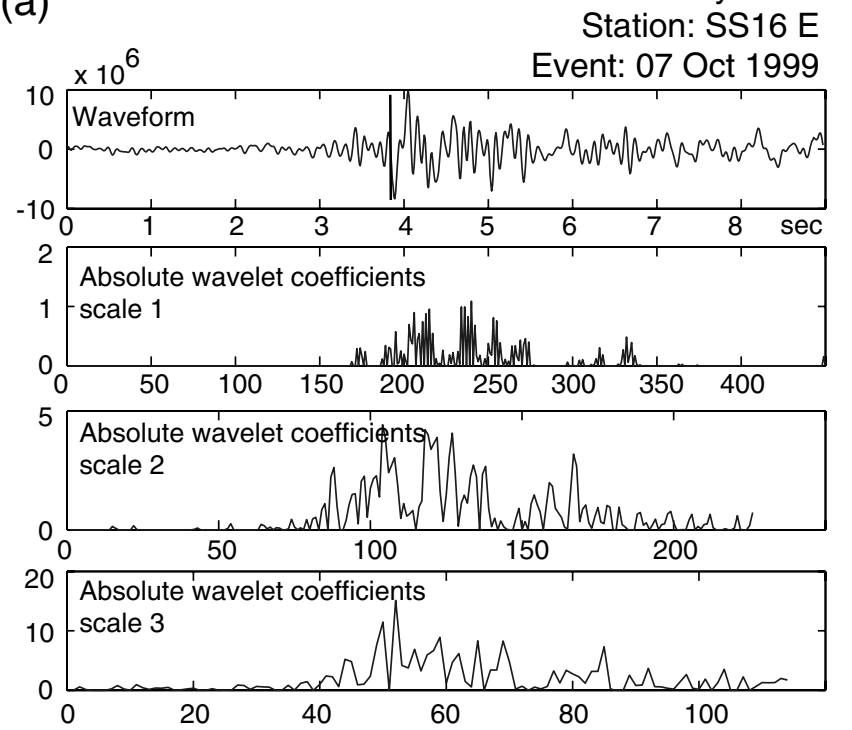

(b)
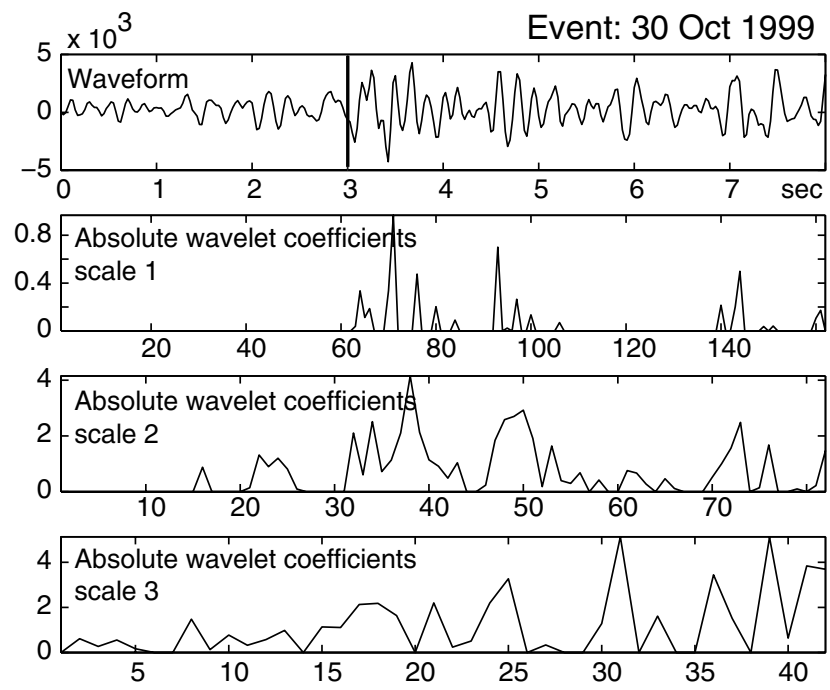

Array: OSA

Station: MATA N
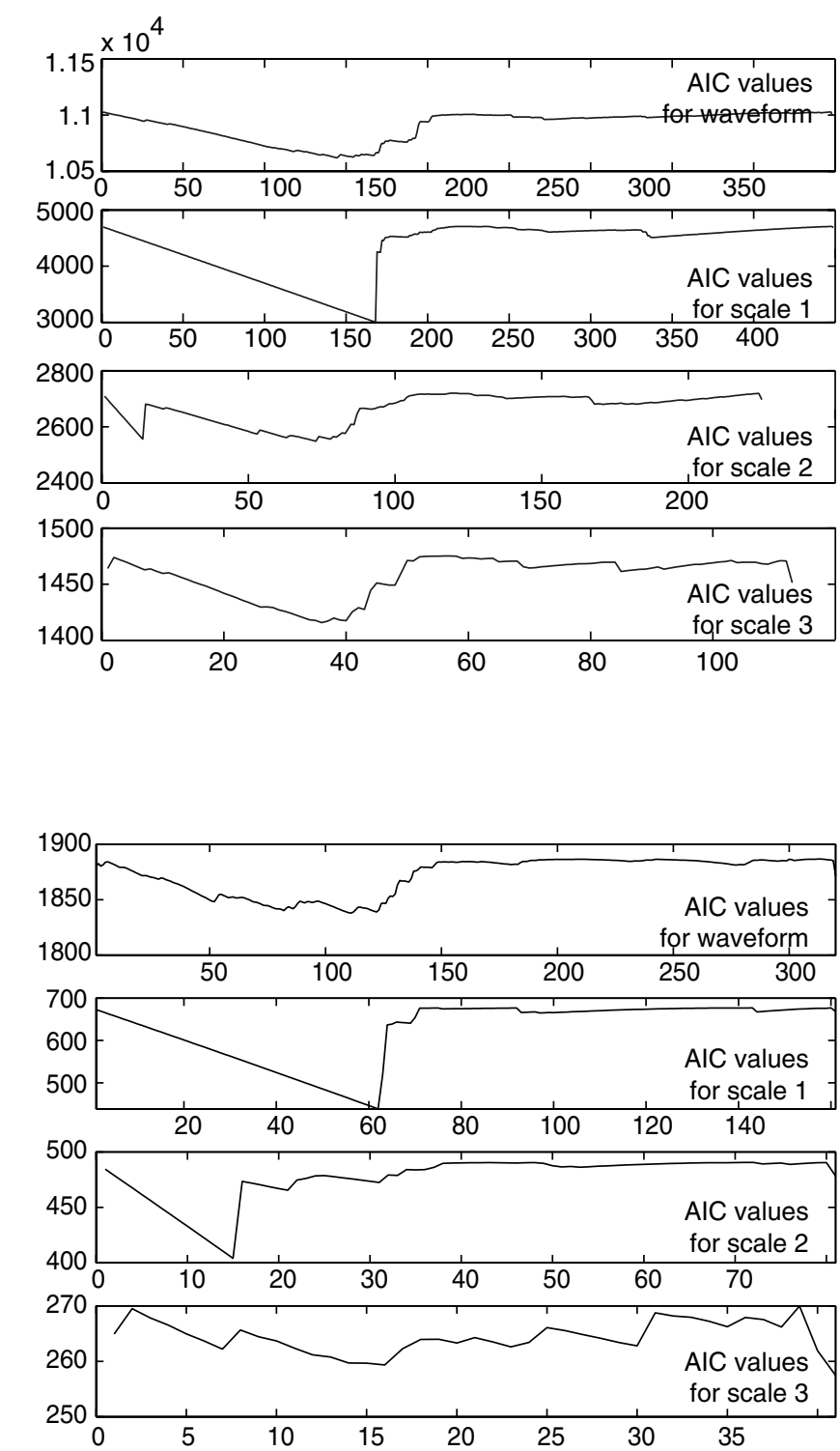

Figure 5. Examples of the wavelet-AIC method to identify an arrival. (a) Waveform and absolute wavelet coefficients for three scales (left column) and their corresponding AIC values (right column) for OBS station SS16 of the OSA array. The handpick is shown by the vertical solid black line on the waveform. Automatic arrival location of the $S$ wave on these waveforms fails due to a precursory phase resulting in multiple AIC minimums. (b) Coefficients and AIC values for land station MATA of the OSA array. Automatic pick fails due to emergent $S$ arrival.

threshold (0.80) cross correlation would yield and an $\sim 2$ and $\sim 3$-fold increase for $P$ and $S$ dts, respectively.

\section{Discussion}

We quantify the reliability of the automatic picker to assign accurate quality factors and explore how the use of the new qualities as mapped to weight would affect our subsequent data processing, for example earthquake relocation and velocity tomography. We have integrated five large amphibious $P$ - and $S$-wave arrival datasets into one exceptionally high-quality set of absolute and differential time data us- ing a combination of quality verification and $\mathrm{CC}$ techniques. Some loss of good arrival times occurs due to the failure of the automatic picker to correctly identify emergent or complex onsets, especially for $S$ waves. The loss is acceptable, however, in order to gain a consistent quality factor for every arrival. On the other hand, loss in data will affect the data coverage, for example, in tomographic inversions. This is discussed below.

\section{Dataset Bias}

We looked for trends and systematic biases in the differences between the original picks and automatic picks. 


\section{(a) OSA}

Event 1: 8/31/00, $9.06 \mathrm{~N} 84.15 \mathrm{~W}$, Depth $36.29 \mathrm{~km}, \mathrm{M} 1.33$ Event 2: $10 / 21 / 99,9.08 \mathrm{~N} 84.17$ W, Depth $33.21 \mathrm{~km}, \mathrm{M} 1.45$

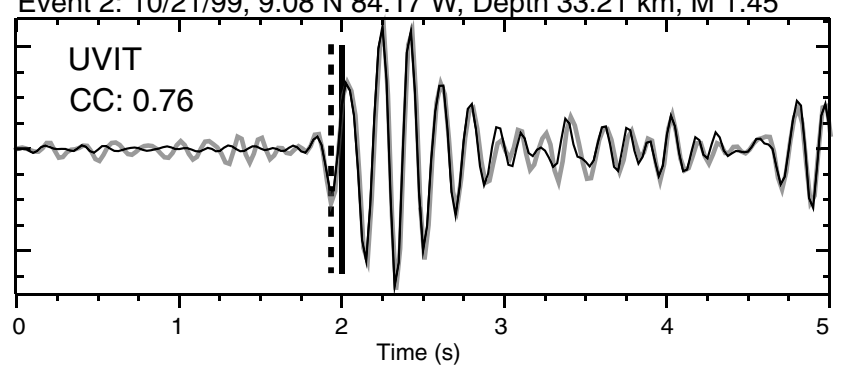

(c) NICAT

Event 1: 03/02/06, $10.37 \mathrm{~N} 86.20 \mathrm{~W}$, Depth $17.1 \mathrm{~km}, \mathrm{M} 2.0$ Event 2: 03/04/06, $10.38 \mathrm{~N} 86.20 \mathrm{~W}$, Depth $13.5 \mathrm{~km}, \mathrm{M} 1.0$

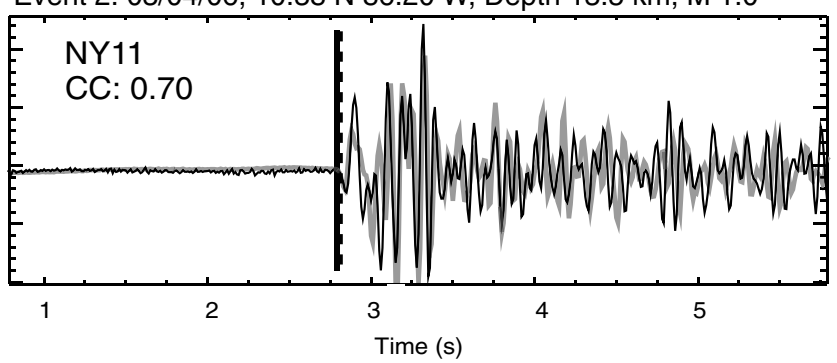

(b) NICOYA

Event 1: 01/10/00, 9.65 N 85.91 W, Depth 30.37 km, M 1.58 Event 2: 01/04/00, 9.67 N 85.92 W, Depth 30.85 km, M 2.66

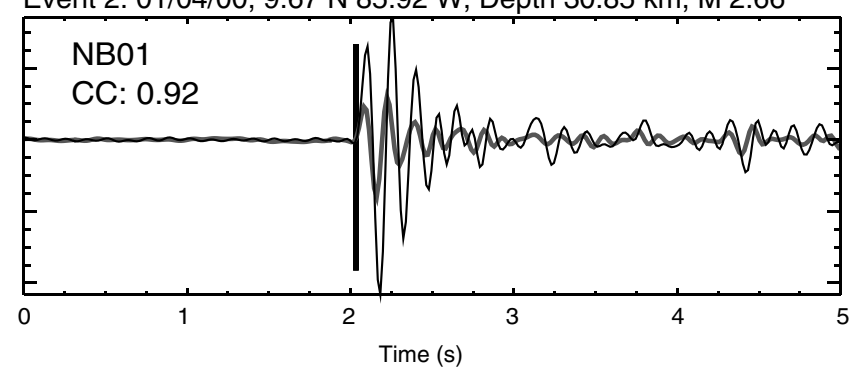

(d) JAC/QUE

Event 1: 05/25/2002, 9.36 N 84.66 W, Depth $15.7 \mathrm{~km}$ Event 2: 05/25/2002, 9.36 N 84.66 W, Depth 17.4 km

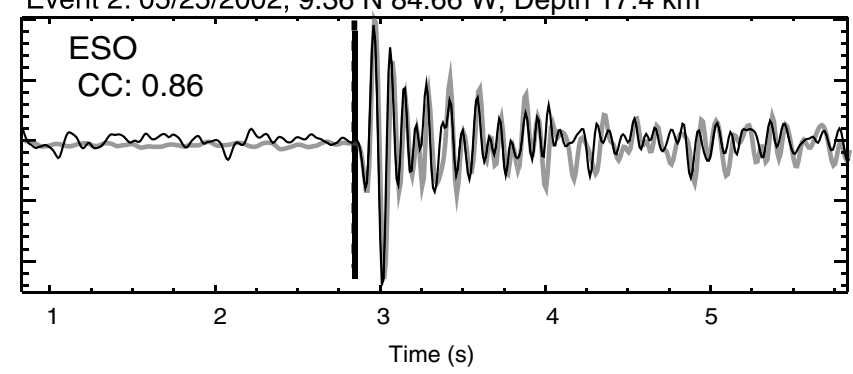

Figure 6. Example of realignment resulting from waveform cross correlation for four arrays. For each, event 1 is shown in black and event 2 in gray. The waveforms are aligned on the adjusted $P$ after bispectrum CC. The $P$ for event 2 is left at the original manual pick (dashed line). The cross-correlation-derived $P$ pick for event 2 is shown by the solid line. Event information and time domain CC coefficients are listed for each waveform. Note that the BCSEIS package allows for direct computation of differential times rather than absolute pick adjustments, and the absolute adjustment shown here is only for illustrative purposes.

Table 3 shows statistical measurements of the distribution of these differences for each of the experiments. Scatter plots and histograms revealed a slight bias toward negative values, indicating that the wavelet-AIC tends to pick late relative to the analyst. There was no evidence of multimodal distributions. Of the five experiments, NICOYA and NICAT lose the largest absolute number of arrivals due to quality 4 and 5 ratings (Fig. 4b,d). The NICOYA and NICAT experiments have the highest standard deviations associated with original pick versus automatic pick time differences (Table 3). NICOYA, however, is also the largest dataset because stations were deployed for a significantly longer time period than the other experiments and had the most analysts with the broadest range of experience picking phase arrivals. Therefore, it is not surprising that the pick quality of NICOYA dataset is most variable. NICAT's poor quality is due to the overall noisier waveforms compared to the other experiments. The poor quality rating of the NICOYA and NICAT datasets significantly diminish the apparent quality of the integrated dataset (Fig. 4f). Excluding the NICOYA and NICAT datasets would increase the percentage of high-quality picks (quality $0-3$ ) to $68 \%$ of the $P$-wave data and $69 \%$ of the $S$-wave data.

Although NICOYA and NICAT show the largest differences between original and automatic picks, overall the means and medians are low for all experiments, with most in the range of being high-quality data $(<0.05 \mathrm{~s})$. There is a large difference between standard deviations reported for all data versus only the high-quality (0-3) data. This is expected because standard deviations around means are sensitive to large outliers. The deviation from the median is quantified using the median absolute deviation (MAD). MAD is calculated by first finding the median of the data residuals and then taking the median of the absolute deviations about that data residual median. MAD is less sensitive to large outliers and better quantifies the statistical dispersion of all data (Table 3). The MAD values for the complete dataset and the high-quality data are similar and low, again suggesting that the larger standard deviations for all the data versus the high-quality subset is caused by outliers which are removed through our quality control scheme.

\section{Effect on Earthquake Location}

To quantify what effect the new quality determinations and removal of poor phase picks would have on earthquake location, we relocated all earthquakes using the original data qualities (i.e., all phases given quality 0 ) and the new data qualities. We calculate locations using VELEST (Kissling et al., 1994) and a 1D model created from previously published minimum 1D models for this region (Quintero and Kissling, 2001; DeShon et al., 2003, 2006; DeShon and Schwartz, 2004; and (E) Table S3, available in the electronic 
Table 3

Data Statistics $\Delta t$ (Original Pick Minus the Automatic Pick) in Seconds

\begin{tabular}{cclcc}
\hline Experiment/Phase/Data & Mean & Median & Standard Deviation & Median Absolute Deviation \\
\hline OSA $^{*} / P^{\dagger} /$ all ${ }^{\ddagger}$ & 0.024 & -0.01 & 1.634 & 0.106 \\
OSA/S/all & 0.347 & -0.04 & 1.856 & 0.2 \\
OSA/P/0-3\| & -0.027 & -0.004 & 0.152 & 0.054 \\
OSA/S/0-3 & -0.068 & -0.04 & 0.184 & 0.095 \\
NICOYA/P/all & -0.569 & -0.025 & 3.242 & 0.142 \\
NICOYA/S/all & -0.22 & -0.24 & 1.52 & 0.317 \\
NICOYA/P/0-3 & -0.026 & 0 & 0.177 & 0.075 \\
NICOYA/S/0-3 & -0.101 & -0.07 & 0.206 & 0.134 \\
QUE/P/all & -0.287 & -0.018 & 1.229 & 0.039 \\
QUE/S/all & -0.229 & -0.214 & 1.343 & 0.215 \\
QUE/P/0-3 & -0.053 & -0.01 & 0.133 & 0.02 \\
QUE/S/0-3 & -0.133 & -0.086 & 0.174 & 0.081 \\
NICAT/P/all & -0.71 & -0.194 & 2.372 & 0.267 \\
NICAT/S/all & -0.317 & -0.335 & 1.587 & 0.339 \\
NICAT/P/0-3 & -0.109 & -0.046 & 0.174 & 0.054 \\
NICAT/S/0-3 & -0.154 & -0.135 & 0.206 & 0.124 \\
JAC/P/all & -0.167 & -0.057 & 1.244 & 0.093 \\
JAC/S/all & -0.255 & -0.295 & 1.462 & 0.278 \\
JAC/P/0-3 & -0.096 & -0.035 & 0.154 & 0.041 \\
JAC/S/0-3 & -0.176 & -0.16 & 0.177 & 0.127 \\
\hline
\end{tabular}

\footnotetext{
*Experiment name.

${ }^{\dagger}$ Seismic phase.

Data included in statistics.

${ }^{\S}$ All, entire data catalog in statistics (all qualities).

${ } 0-3$ : only qualities $0-3$ in statistics.
}

supplement). Our new qualities range from $0-4$ and are used directly in VELEST to describe the relative weighting of the phases. However, phases of quality 4 are down-weighted to 0 in the inversion process. The numbers of arrivals for $P$ and $S$ are given in Table 4. Note that in relocations using either the original or new qualities result in hypocentral location changes from the original catalog solutions due to differences in velocity models from the original processing and the use of a different relocation technique. This relocation method does not use differential times or cross-correlation information.

We compared both sets of relocations to the original cata$\log$ locations and to each other. The mean, median, and standard deviation of changes in latitude, longitude, depth, and origin time were calculated for each of the five experiments (E) Table S4, available in the electronic supplement). Changes in hypocentral distance, number of $P$ and $S$ waves, and root mean square (rms) for each array are shown in Table 4.

For all arrays, analysis of the new hypocenters show that the subset data with the new qualities (newq) and the data with the original qualities (oldq) produce statistically similar movements in their relocations results (Tables 4, (E) S4, available in the electronic supplement). The median distance difference between the relocated hypocenters produced by the originally weighted data and the newly assigned data quality ranges between 1.8 and $4.6 \mathrm{~km}$, while the shift of the oldq and newq relocations relative to the original catalog locations are similar in magnitude. The overall rms values using the oldq and newq catalogs are also very similar for each experiment. The removal of a substantial amount of data did not significantly affect the relocations in a statistical sense, in part because large residuals are down-weighted during the inversion process. Even with very different initial weighting schemes, the final set of arrivals used to relocate the oldq and newq catalogs were statistically the same. These results do suggest, however, that location uncertainty for the $1 \mathrm{D}$ relocations is on the order of a few kilometers for all of the experiments.

\section{Effect on Seismic Velocity Modeling}

Precise $P$ - and $S$-arrival times are required for the inversion of travel-time data to derive seismic velocity. Because of the nonuniqueness of inversion solutions, the quality of the initial input data is especially important. The inversion of poor quality data can still result in minimized final residuals and a model that may have low rms and reasonable variance, yet not realistically describe the velocity structure. We test the effect of including all data of unknown quality versus limiting the dataset to only data we know is high quality into a double-difference seismic velocity tomographic inversion (tomoDD, Zhang, 2003; Zhang and Thurber, 2003).

The inversion of the high-quality subset of the CRSEIZE and SFB data was performed first. Details of procedures for this inversion are described in Moore-Driskell (2012). The qualities from this study were translated into weights ranging from 0 (poor) to 1 (best) for the $P$ and $S$ picks. These weights (Table 2) were used in the tomography algorithm. A second inversion was performed using the same event subset but 
Table 4

Data Statistics Comparing Calculations Using the Old Arrival Pick Qualities and the New Pick Qualities

\begin{tabular}{|c|c|c|c|c|c|c|c|c|c|c|}
\hline \multirow[b]{2}{*}{ Experiment } & \multicolumn{3}{|c|}{$\begin{array}{l}\text { Change in Hypocentral } \\
\text { Distance Location }\end{array}$} & \multicolumn{3}{|c|}{$\begin{array}{l}\text { Change in } \\
\text { Origin Time }\end{array}$} & \multicolumn{3}{|c|}{ rms* } & \multirow{2}{*}{$\begin{array}{c}\begin{array}{c}\text { Relocated } \\
\text { Events }\end{array} \\
\text { Number }\end{array}$} \\
\hline & $\begin{array}{r}\text { Mean } \\
(\mathrm{km})\end{array}$ & $\begin{array}{c}\text { Median } \\
(\mathrm{km})\end{array}$ & $\begin{array}{c}\text { Standard } \\
\text { Deviation }(\mathrm{km})\end{array}$ & $\begin{array}{c}\text { Mean } \\
(\mathrm{s})\end{array}$ & $\begin{array}{c}\text { Median } \\
(\mathrm{s})\end{array}$ & $\begin{array}{c}\text { Standard } \\
\text { Deviation }(\mathrm{s})\end{array}$ & Mean & Median & $\begin{array}{r}\text { Standard } \\
\text { Deviation } \\
\end{array}$ & \\
\hline $\begin{array}{l}\text { OSA oldq relocations vs. } \\
\text { original locations }\end{array}$ & 13.2 & 11.2 & 9.4 & 1.8 & 1.6 & 1.2 & 0.9 & 0.7 & 0.6 & 943 \\
\hline $\begin{array}{l}\text { OSA newq relocations vs. } \\
\text { original locations }\end{array}$ & 13.4 & 11.3 & 10.0 & 1.9 & 1.7 & 1.3 & 0.9 & 0.7 & 0.7 & 943 \\
\hline $\begin{array}{l}\text { OSA oldq vs. newq } \\
\text { relocations }\end{array}$ & 4.5 & 3.5 & 3.8 & 0.1 & 0.1 & 0.4 & 0.0 & 0.0 & 0.3 & \\
\hline $\begin{array}{l}\text { NICOYA oldq relocations vs. } \\
\text { original locations }\end{array}$ & 3.8 & 2.7 & 4.5 & 0.4 & 0.3 & 0.6 & 0.3 & 0.2 & 0.5 & 10,314 \\
\hline $\begin{array}{l}\text { NICOYA newq relocations vs. } \\
\text { original locations }\end{array}$ & 4.0 & 2.7 & 4.8 & 0.4 & 0.3 & 0.6 & 0.3 & 0.2 & 0.5 & 10,311 \\
\hline $\begin{array}{l}\text { NICOYA oldq vs. newq } \\
\text { relocations }\end{array}$ & 1.4 & 0.7 & 7.6 & 0.0 & 0.0 & 0.3 & 0.0 & 0.0 & 0.2 & \\
\hline $\begin{array}{l}\text { QUE oldq relocations vs. } \\
\text { original locations }\end{array}$ & 9.6 & 5.8 & 14.0 & 0.9 & 0.5 & 1.9 & 0.4 & 0.3 & 0.6 & 2,014 \\
\hline $\begin{array}{l}\text { QUE newq relocations vs. } \\
\text { original locations }\end{array}$ & 8.6 & 4.9 & 14.6 & 0.3 & 0.1 & 0.6 & 0.4 & 0.3 & 0.6 & 2,019 \\
\hline $\begin{array}{l}\text { QUE oldq vs. newq } \\
\text { relocations }\end{array}$ & 5.8 & 3.5 & 11.3 & 0.3 & 0.2 & 1.2 & 0.0 & 0.0 & 0.4 & \\
\hline $\begin{array}{l}\text { JAC oldq relocations vs. } \\
\text { original locations }\end{array}$ & 3.5 & 2.6 & 4.7 & 1.1 & 1.1 & 0.7 & 0.2 & 0.2 & 0.3 & 2,689 \\
\hline $\begin{array}{l}\text { JAC newq relocations vs. } \\
\text { original locations }\end{array}$ & 3.4 & 2.4 & 4.6 & 0.3 & 0.3 & 0.7 & 0.2 & 0.2 & 0.4 & 2,690 \\
\hline JAC oldq vs. newq relocations & 2.4 & 1.8 & 2.7 & 1.4 & 1.5 & 0.6 & 0.0 & 0.0 & 0.2 & \\
\hline $\begin{array}{l}\text { NICAT oldq relocations vs. } \\
\text { original locations }\end{array}$ & 6.9 & 5.0 & 9.7 & 0.2 & 0.1 & 1.0 & 0.4 & 0.3 & 0.9 & 1,446 \\
\hline $\begin{array}{l}\text { NICAT newq relocations vs. } \\
\text { original locations }\end{array}$ & 6.8 & 4.9 & 9.2 & 0.2 & 0.1 & 0.9 & 0.4 & 0.3 & 0.8 & 1,442 \\
\hline $\begin{array}{l}\text { NICAT oldq vs. newq } \\
\text { relocations }\end{array}$ & 5.7 & 4.6 & 6.9 & 0.0 & 0.0 & 0.4 & 0.3 & 0.2 & 0.4 & \\
\hline
\end{tabular}

*rms values for the original locations are set to 0.0 .

with the $P$ and $S$ weighting all set to 1 . We will refer to this second tomographic test as the equal-weights data for simplicity of description. Catalog differential times were calculated so that the differential times also reflected the new qualities. Both inversions used identical cross-correlation data and weighting derived using BCSEIS.

rms, model variance, and data variance between the resulting two models differ little, though weighted data has slightly lower rms and model/data variance. These similar statistics reflect the double-difference tomography algorithm's effectiveness at minimizing residuals even with a poorer quality/unweighted dataset through the use of residual weighting. In this case, a residual spread is calculated (a robust equivalent to standard deviation; see Zhang, 2003). A cutoff value is assigned to the spread, usually between 3 and 6 . If the residuals approach the cutoff spread value, the residual weighting drops to zero. This essentially removes non-Gaussian outliers from being used in the inversion for both the unweighted and the weighted inversion.

Typically for local earthquake DD tomographic inversions, only events with at least eight recorded $P$-wave arrivals are used. When eliminating the poor quality data, arrivals are lost and as a result the number of events that can be used decreases, thus reducing the data coverage. For the CRSEIZE/ SFB dataset this was substantial with about $31 \%$ of the events lost because of lack of enough $P$ arrivals. Table 5 shows the numbers of events for each experiment before and after the quality adjustments. Because of this decrease in the amount of data we elected to perform the inversion with the poorest data, but down-weighting it to 0.1 in the inversion parameters. Because all of the datasets have been previously used in other

Table 5

Number of Events before and after Weighting

\begin{tabular}{cccc}
\hline Experiment & $\begin{array}{c}\text { Arrival Not Weighted } \\
\text { (Number of Events) }\end{array}$ & $\begin{array}{c}\text { Arrivals Weighted } \\
\text { (Number of Events) }\end{array}$ & $\begin{array}{c}\text { Events } \\
\text { Lost* }(\%)\end{array}$ \\
\hline OSA & 328 & 219 & 33 \\
NICOYA & 1081 & 772 & 29 \\
QUE & 529 & 393 & 26 \\
NICAT & 697 & 315 & 55 \\
JAC & 602 & 545 & 9 \\
Integrated & 3237 & 2244 & 31 \\
\hline
\end{tabular}

*Lost events are a result of poor-quality arrivals being removed from the dataset and thus events are removed because they now have $<8 P$ arrivals. 


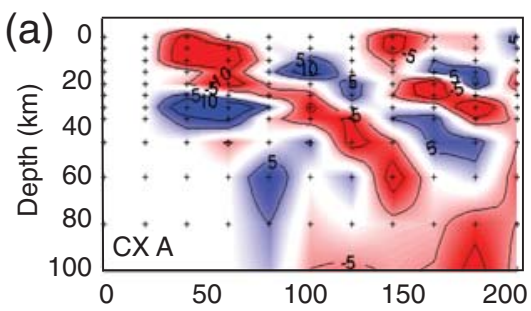

(b)
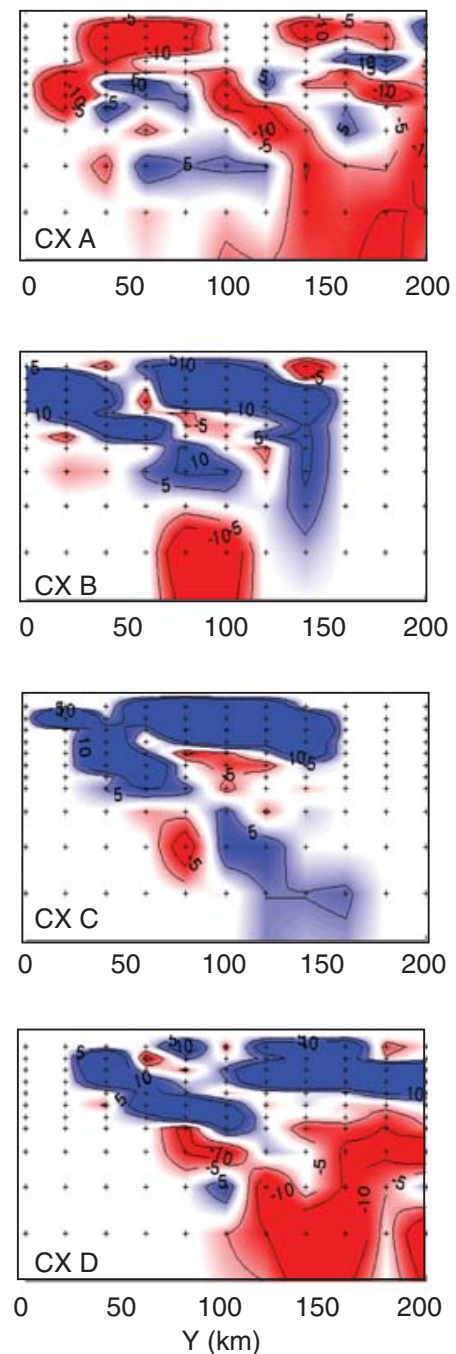

Relative Velocity (\%)

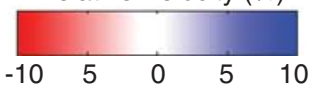

(c)
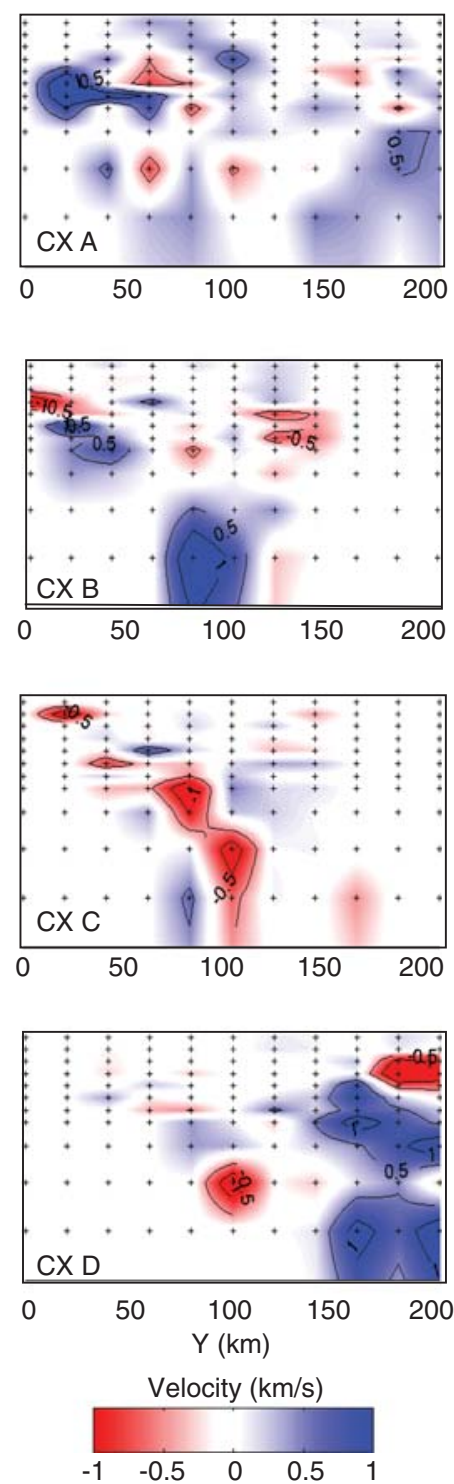

Figure 7. Comparison of weighted data tomographic images versus unweighted data tomographic images. (a) Weighted quality data: seismic velocity perturbations (\%) from the 1D starting model of the inversion performed with the new weighting based on the quality determination. (b) Unweighted data: the inversion using the data all weighted to 1 . Contours are shown for $\pm 15 \%$, $\pm 10 \%$, and $\pm 5 \%$. (c) The difference in the absolute velocity of the weighted minus the unweighted model in $\mathrm{km} / \mathrm{s}$. The Figure 1 map shows the locations of the cross sections. The cross-section name is indicated in the lower left corner of the plot. Unweighted model shows significant differences in locations of perturbations and perturbation amplitudes.

studies and have been analyzed by people as opposed to solely automatic picks, this approach is probably valid for this and other seismic studies, but we feel the best dataset will exclude poorest (quality 4) data. However, using the dataset with the poorer, down-weighted data, we can directly compare the inversions using the weighted data and the unweighted, that is using the same event list and arrivals for both. This approach will eliminate the differences caused by a smaller event cata$\log$ and focus on the variance caused by the new weighting scheme. For completeness, we also invert the data with the poorest data removed as we would in a typical tomographic inversion using this data-weighting procedure (E) Fig. S3, available in the electronic supplement). For all cases, events with a greatest $P$-wave azimuthal separation (GAP) of $\leq 180^{\circ}$, and events that moved a great deal during relocation with the VELEST program were also removed prior to inversion.

Even though the statistics differ little, differences in the final output velocity models are quite large. Figure 7 shows the resulting tomographic images for seismic velocity using the high-quality weights (column A) and the equal-weights data (column B). Inversion of the equal-weights data introduces velocity perturbations in areas not resolved in the quality-weights inversion. For example, in all the cross sections shown in Figure 7, the equal-weights inversion shows strong velocity perturbations in the oceanic mantle. In areas of highest resolution, the major characteristics of the cross sections 
are similar, but the amplitudes of the perturbations in the equal-weights data are much larger, in many places $\pm 10 \%$ or more from the 1D minimum starting model. The difference in the quality-weighted and equal-weighted absolute velocities in $\mathrm{km} / \mathrm{s}$ can be locally large (Fig. 7, column C). In many locations the two models differ as much as $\pm 1.5 \mathrm{~km} / \mathrm{s}$. For context, if a velocity of $7.0 \mathrm{~km} / \mathrm{s}$ is reduced by $1.5 \mathrm{~km} / \mathrm{s}$ in the equal-weights tomography, there is a velocity reduction of $22 \%$ between models. This magnitude of differences between models is unreasonable. With this comparison it is obvious that the inversion is trying to correct for the poorer quality by introducing unrealistic velocities into the model. The equal-weights model contains noise due to the identical initial weighting of high- and low-quality data. However, there is no statistical indication (rms, etc.) that would reveal this source of noise. In other words, it would be possible to misinterpret the resulting noisy model. Additionally, damping parameters in the inversion could also affect the magnitude of the velocity anomalies in the models. (E) We show in Figure S4 (available in the electronic supplement) that increasing the damping in the inversion does not act to decrease the unrealistic anomalies seen in the equally weighted inversion.

\section{Conclusions}

Many seismic studies rely on the accuracy of travel-time datasets, and the phase quality verification method outlined here can be easily applied to consistently quantify the quality of pre-existing datasets in which waveforms are available. The wavelet-AIC method allows quick and consistent verification of pre-existing phase onset quality, which is valuable when many people have analyzed the data and inconsistent quality factors result. We would have been unable to visually assess the quality of every arrival pick in a timely fashion. The new quality factors can be easily transformed into weights for inclusion in studies that use such data. As other studies have shown, the use of CC methods can also reduce phase onset errors. The joint approach of using autodetectors to verify pick quality of large datasets and CC methods to improve absolute and/or differential times is a unique solution to the increasingly common problem of producing welldescribed, high-quality arrival-time datasets from large seismic experiments.

The quality-controlled set of $P$ - and $S$-pick onsets and waveform CC derived differential times for the Nicaragua/ Costa Rica amphibious networks are being used to develop 3D velocity and attenuation tomographic images of the Middle America subduction zone. Though many phases were lost or reweighted using quality determination, relocation within a 1D velocity model suggests that only minor location changes result for well-recorded earthquakes. Comparison to tomographic images created using the qualityweighted data versus equal-weighted data, however, shows significant addition of unresolved velocity perturbations and greatly increased perturbation amplitudes with the equal- weighted data. This can have substantial effect on interpretation of tomographic images. As larger experiments and bigger datasets become widely available to the community, efficient quality assessment techniques will become more necessary.

\section{Data and Resources}

Seismograms used in this study were collected as part of the CRSEIZE and SFB experiments. The land CRSEIZE seismograms are available through the Incorporated Research Institutions for Seismology IRIS Data Management Center at www.iris.edu (last accessed August 2012). CRSEIZE OBS data are available by request from LeRoy Dorman, Susan Schwartz, or H. R. DeShon. CRSEIZE seismic instrumentation was provided by Scripps Institution of OceanographyUniversity of California San Diego, University of California Santa Cruz, and the IRIS Program for Array Seismic Studies of the Continental Lithosphere (PASSCAL) Instrument Center. SFB seismograms can be requested from W. Rabbel. The Geophysical Instrument Pool Potsdam (GIPP) at Geoforschungszentrum Potsdam provided land seismometers for the JAC, QUE, and Nicaragua amphibious array (NICAT) arrays and Christian Albrechts University of Kiel and former Leibniz Institute of Marine Sciences at the University of Kiel (IFM-GEOMAR) provided the OBS stations. The Antelope database is a product of Boulder Real Time Technologies (www.brtt.com, last accessed April 2013).

Figure 1 was made using the Generic Mapping Tools version 4.2.1 (Wessel and Smith, 1998). The wavelet-AIC program was run using MATLAB version R2009b. Figures 2 and 3 were created in MATLAB version R2009b. SAC (Goldstein et al., 2003) was used for data processing. Antelope software, a product of Boulder Real Time Technologies, and SEISAN (Havskov and Ottemöller, 2005) were used for waveform management and initial locations.

\section{Acknowledgments}

We would like to gratefully acknowledge the faculty, staff, and students of University of California-Santa Cruz, the Observatorio Vulcanológico y Sismológico de Costa Rica, and Scripps Institution of Oceanography for their work collecting the CRSEIZE data; and the work of faculty, students, and staff of Christian Albrechts University of Kiel and GEOMAR who operated the SFB experiments. The acquisition and initial processing of the data from the JAC, QUE, and NICAT arrays were sponsored by the German Science Foundation (DFG) within the Collaborative Research Program SFB 574. Thanks to the Geophysical Instrument Pool Potsdam (GIPP) at Geoforschungszentrum Potsdam for providing the land seismometers for the JAC, QUE, and NICAT arrays and IFM-GEOMAR for the OBS stations. We thank Haijiang Zhang for providing the programs for the waveletAIC picker and tomoDD. We also thank M. Protti, V. Gonzalez, S. Y. Schwartz, S. L. Bilek, A. V. Newman, A. Ghosh, G. T. Farmer, A. M. Thomas, M. Avants, and C. Benoit, analysts who exhibited the patience to pick the CRSEIZE datasets. Support for this project was provided by National Science Foundation (NSF-OCE) (OCE-0841077 to HRD). 


\section{References}

Akaike, H. (1973). Information theory and an extension of the maximum likelihood principle, in 2nd International Symposium on Information Theory, B. Petrov and F. Csaki (Editors), Budapest Akademiai Kiado, 267-281.

Anant, S. K., and F. U. Dowla (1997). Wavelet transform methods for phase identification in three-component seismogram, Bull. Seismol. Soc. Am. 87, 1598-1612.

Arroyo, I. G., S. Husen, E. R. Flueh, J. Gossler, E. Kissling, and G. E. Alvarado (2009). Three-dimensional $P$-wave velocity structure on the shallow part of the Central Costa Rican margin from local earthquake tomography using off- and onshore arrays, Geophys. J. Int. 179, $827-849$.

Barckhausen, U., C. R. Ranero, R. von Huene, S. C. Cande, and H. A. Roeser (2001). Revised tectonic boundaries in the Cocos Plate off Costa Rica: Implications for the segmentation of the convergent margin and for plate tectonic models, J. Geophys. Res. 106, 19,207-19,220.

Bilek, S. L., S. Y. Schwartz, and H. R. DeShon (2003). Control of seafloor roughness on earthquake rupture behavior, Geology 31, 455-458.

Currie, C. A., R. D. Hyndman, K. Wang, and V. Kostoglodov (2002). Thermal models of the Mexico subduction zone: Implications for the megathrust seismogenic zone, J. Geophys. Res. 107, no. B12, 2370, doi: 10.1029/2001JB000886.

DeShon, H. R. (2004). Seismogenic zone structure along the Middle America subduction zone, Costa Rica, Ph.D. Thesis, University of California-Santa Cruz, Santa Cruz, California, 359 pp.

DeShon, H. R., and S. Y. Schwartz (2004). Evidence for serpentinization of the forearc mantle wedge along the Nicoya Peninsula, Costa Rica, Geophys. Res. Lett. 31, L21611, doi: 10.1029/2004GL021179.

DeShon, H. R., S. Y. Schwartz, S. L. Bilek, L. M. Dorman, V. Gonzalez, J. M. Protti, E. R. Flueh, and T. H. Dixon (2003). Seismogenic zone structure of the southern Middle America Trench, Costa Rica, J. Geophys. Res. 108, doi: 10.1029/2002JB002294.

DeShon, H. R., S. Y. Schwartz, L. M. Dorman, A. V. Newman, V. Gonzalaz, M. Protti, T. Dixon, E. Norabuena, and E. Flueh (2006). Seismogenic zone structure along the Middle America Trench, Nicoya Peninsula, Costa Rica, from 3D local earthquake tomography using $P$ - and S-wave data, Geophys. J. Int. 164, 109-124.

Diehl, T., and E. Kissling (2007). Users Guide for consistent phase picking at local to regional scales (Appendix C of Ph.D. Thesis of T. Diehl), Tech. Rep., ETH Zurich.

Diehl, T., N. Deichmann, E. Kissling, and S. Husen (2009). Automatic $S$-wave picker for local earthquake tomography, Bull. Seismol. Soc. Am. 99, 1906-1920.

Di Stefano, R., F. Aldersons, E. Kissling, P. Baccheschi, C. Chiarabba, and D. Giardini (2006). Automatic seismic phase picking and consistent observation error assessment: Application to the Italian seismicity, Geophys. J. Int. 165, 121-134, doi: 10.1111/j.1365-246X.2005. 02799.x.

Dinc, A. N., I. Koulakov, M. Thorwart, W. Rabbel, E. R. Flueh, I. Arroyo, W. Taylor, and G. Alvarado (2010). Local earthquake tomography of Central Costa Rica: Transition from seamount to ridge subduction, Geophys. J. Int. 183, 286-302, doi: 10.1111/j.1365246X.2010.04717.x.

Dinc, A. N., W. Rabbel, E. Flueh, and W. Taylor (2011). Mantle wedge hydration in Nicaragua from local earthquake tomography, Geophys. J. Int. 186, 99-112.

Dodge, D. A., G. C. Beroza, and W. L. Ellsworth (1995). Evolution of the 1992 Landers, California foreshock sequence and its implications for earthquake nucleation, J. Geophys. Res. 100, 9865-9880.

Du, W., C. Thurber, and D. Eberhart-Phillips (2004). Earthquake relocation using cross-correlation time delay estimates verified with the bispectrum method, Bull. Seismol. Soc. Am. 94, 856-866.

Fisher, A. T., R. N. Harris, C. Stein, K. Wang, M. Hutnak, A. Cherkaoui, M. Pfender, R. Cleary, E. Silver, C. G. Wheat, R. Bodzin, M. Underwood, C. Moser, R. Kelly, P. Friedmann, Y. Stewart, and K. Jones (2001).
Heat flow on the incoming plate offshore Nicoya, Costa Rica margin: Implications for hydrothermal circulation and the thermal state of the subducting plate, AGU Fall Meeting Abstracts, Vol. 1, 922 pp.

Ghosh, A., A. V. Newman, A. M. Thomas, and G. T. Farmer (2008). Interface locking along the subduction megathrust from microseismicity near Nicoya, Costa Rica, Geophys. Res. Lett. 35, L01301, doi: 10.1029/2007GL031617.

Goldstein, P., D. Dodge, M. Firpo, and L. Minner (2003). SAC2000: Signal processing and analysis tools for seismologists and engineers, in Invited Contribution to "The IASPEI International Handbook of Earthquake and Engineering Seismology," W. H. K. Lee, H. Kanamori, P. C. Jennings, and C. Kisslinger (Editors), Academic Press, London, 1943 pp.

Got, J.-L., J. Frechet, and F. Klein (1994). Deep fault plane geometry inferred from multiplet relative relocation beneath the south flank of Kilauea, J. Geophys. Res. 99, 15,375-15,386.

Harris, R. N., and K. Wang (2002). Thermal models of the Middle America Trench at the Nicoya Peninsula, Costa Rica, Geophys. Res. Lett. 29, no. 21, 6-1-6-4, doi: 10.1029/2002GL015406.

Haslinger, F., and E. Kissling (2001). Investigating effects of 3-D ray tracing methods in local earthquake tomography, Phys. Earth Planet. Int. 123, $103-114$.

Havskov, J., and L. Ottemöller (2005). SEISAN: The Earthquake Analysis Software for Windows, Solaris and LINUX, version 8.1, University of Bergen, Norway.

Husen, S., and E. Kissling (2001). Local earthquake tomography between rays and waves: Fat ray tomography, Phys. Earth Planet. Int. 123, 127-147.

Husen, S., T. Diehl, and E. Kissling (2009). The effects of data quality in local earthquake tomography: Application to the Alpine region, Geophysics 74, no. 6, doi: 10.1190/1.3237117.

Hyndman, R. D., and K. Wang (1993). Thermal constraints on the zone of major thrust earthquake failure: The Cascadia subduction zone, J. Geophys. Res. 98, 2039-2060.

Hyndman, R. D., M. Yamano, and D. A. Oleskevich (1997). The seismogenic zone of subduction thrust faults, Island Arc 6, 244-260.

Kennett, B. L. N., and E. R. Engdahl (1991). Travel times for global earthquake location and phase identification, Geophys. J. Int. 105, 429-465.

Kissling, E., W. L. Ellsworth, D. Eberhart-Phillips, and U. Kradolfer (1994). Initial reference models in local earthquake tomography, J. Geophys. Res. 99, 19,635-19,646, VELEST Version 3.1 (10.4.95).

Kitagawa, G., and H. Akaike (1978). A procedure for the modeling of nonstationary time series, Ann. Inst. Stat. Math. 30, Part B, 351-363.

Leonard, M. (2000). Comparison of manual and automatic onset time picking, Bull. Seismol. Soc. Am. 90, 1384-1390.

Leonard, M., and B. L. N. Kennett (1999). Multi-component autoregressive techniques for the analysis of seismograms, Phys. Earth Planet. Int. 113, 247-264.

Lienert, B. R. E., and J. Havskov (1995). A computer program for locating earthquakes both locally and globally, Seismol. Res. Lett. 66, 26-36.

Maeda, N. (1985). A method for reading and checking phase times in autoprocessing system of seismic wave data, Zisin_Jishin 38, 365-379.

Moore-Driskell, M. (2012). 3D double difference tomography of the middle America subduction zone beneath Nicaragua and Costa Rica, Ph.D. Thesis University of Memphis, Memphis, Tennessee.

Newman, A. V., S. Y. Schwartz, V. Gonzalez, H. DeShon, J. Protti, and L. M. Dorman (2002). Along-strike variability in the seismogenic zone below Nicoya Peninsula, Costa Rica, Geophys. Res. Lett. 29, no. 20, doi: 10.1029/2002GL015409.

Podvin, P., and I. Lecomte (1991). Finite difference computation of travel times in very contrasted velocity models: A massively parallel approach and its associated tools, Geophys. J. Int. 105, 271-284.

Poupinet, G., W. L. Ellsworth, and J. Fréchet (1984). Monitoring velocity variations in the crust using earthquake doublets: An application to the Calaveras fault, California, J. Geophys. Res. 89, 5719-5731. 
Protti, M., F. Güendel, and E. Malavassi (2001). Evaluación del potencial sísmico de la Península de Nicoya, Editorial Fundación UNA, Heredia, Costa Rica.

Protti, M., F. Güendel, and K. McNally (1994). The geometry of the WadatiBenioff zone under southern Central America and its tectonic significance: Results from a high-resolution local seismographic network, Phys. Earth Planet. Int. 84, 271-287, doi: 10.1016/0031-9201(94) 90046-9.

Protti, M., F. Güendel, and K. McNally (1995). Correlation between the age of the subducting Cocos plate and the geometry of the Wadati-Benioff zone under Nicaragua and Costa Rica, in Geologic and Tectonic Development of the Caribbean Plate Boundary in Southern Central America, P. Mann (Editor), Spec. Pap. Geol. Soc. Am., Vol. 295, 309-326.

Quintero, R., and E. Kissling (2001). An improved $P$-wave velocity reference model for Costa Rica, Geofisc. Int. 40, 3-19.

Ranero, C. R., A. Villaseñor, J. Phipps Morgan, and W. Weinrebe (2005). Relationship between bend-faulting at trenches and intermediate-depth seismicity, Geochem. Geophys. Geosyst. 6, Q12002, doi: 10.1029/ 2005 GC000997.

Reading, A. M., W. Mao, and D. Gubbins (2001). Polarization filtering for automatic picking of seismic data and improved converted phase detection, Geophys. J. Int. 147, 227-234.

Rowe, C. A., R. C. Aster, B. Borchers, and C. L. Young (2002). An automatic, adaptive algorithm for refining phase picks in large seismic data sets, Bull. Seismol. Soc. Am. 92, 1660-1674.

Rubin, A., D. Gillard, and J.-L. Got (1998). A re-examination of seismicity associated with the January 1983 dike intrusion at Kilauea volcano, Hawaii, J. Geophys. Res. 103, 10,003-10,015.

Rychert, C. A., K. M. Fischer, G. A. Abers, T. Plank, E. M. Syracuse, J. M. Protti, V. Gonzalez, and W. Strauch (2008). Strong along-arc variations in attenuation in the mantle wedge beneath Costa Rica and Nicaragua, Geochem. Geophys. Geosyst. 9, Q10S10, doi: 10.1029/ 2008GC002040.

Sauter, A. W., and L. M. Dorman (1995). A locking compass for determining the orientation of ocean bottom instrumentation, Eos Trans. AGU (Fall Meet. Suppl.), 76, no. 46, F367.

Schwartz, S. Y., and H. R. DeShon (2007). Evidence for multiple mechanical transitions along the updip limit, Nicoya Peninsula, Costa Rica, in The Seismogenic Zone of Subduction Thrust Faults, T. Dixon and J. C. Moore (Editors), Columbia University Press, New York, 576-599.

Shearer, P. M. (1997). Improving local earthquake locations using the L1 norm and waveform cross correlation: Application to the Whittier Narrows, California, aftershock sequence, J. Geophys. Res. 102, no. B4, 8269-8283.

Sleeman, R., and T. van Eck (1999). Robust automatic $P$-phase picking: An on-line implementation in the analysis of broadband seismogram recordings, Phys. Earth Planet. Int. 113, 265-275.

Syracuse, E. M., G. A. Abers, K. Fischer, L. MacKenzie, C. Rychert, M. Protti, V. González, and W. Strauch (2008). Seismic tomography and earthquake locations in the Nicaraguan and Costa Rican upper mantle, Geochem. Geophys. Geosyst. 9, Q07S08, doi: 10.1029/ 2008GC001963.

Takanami, T., and G. Kitagawa (1988). A new efficient procedure for the estimation of onset times of seismic waves, J. Phys. Earth 36, 267-290.

Takanami, T., and G. Kitagawa (1991). Estimation of the arrival times of seismic waves by multivariate time series models, Ann. Inst. Stat. Math. 43, 407-433.
Thurber, C. H. (1983). Earthquake locations and three-dimensional crustal structure in the Coyote Lake area, central California, J. Geophys. Res. 88, 8226-8236.

Um, J., and C. H. Thurber (1987). A fast algorithm for two-point seismic ray tracing, Bull. Seismol. Soc. Am. 77, 972-986.

Vidale, J. E. (1986). Complex polarization analysis of particle motion, Bull. Seismol. Soc. Am. 76, 1393-1405.

Virieux, J., V. Farra, and R. Madariaga (1988). Ray tracing for earthquake location in laterally heterogeneous media, J. Geophys. Res. 93, 65856599.

Von Huene, R., J. Bialas, E. Flueh, B. Cropp, T. Csernok, E. Fabel, J. Hoffman, K. Emeis, P. Holler, G. Jeschke, C. Leandro M., I. Peréz Fernandéz, J. Chavarria S., A. Florez H., D. Escobedo Z., R. León, and O. Barrios L. (1995). Morphotectonics of the Pacific convergent margin of Costa Rica, Spec. Pap. Geol. Soc. Am. 295, 291-308.

Waldhauser, F., and W. L. Ellsworth (2000). A double-difference earthquake location algorithm; method and application to the northern Hayward fault, California, Bull. Seismol. Soc. Am. 90, 1353-1368.

Wessel, P., and W. H. F. Smith (1998). New, improved version of the Generic Mapping Tools released, Eos Trans. Am. Geophys. Union 79, 579.

Yokota, T., S. Zhou, M. Mizoue, and I. Nakamura (1981). An automatic measurement of the arrival time of seismic waves and its application to an on-line processing system, Bull. Earthq. Res. Inst. Univ. Tokyo 55, 449-484.

Zhang, H. (2003). Double-difference seismic tomography method and its applications, Ph.D. thesis, University of Wisconsin-Madison.

Zhang, H., and C. Thurber (2003). Double-difference tomography: The method and its application to the Hayward fault, California, Bull. Seismol. Soc. Am. 93, 1875-1889.

Zhang, H., C. Thurber, and C. Rowe (2003). Automatic $P$-wave arrival detection and picking with multiscale wavelet analysis for singlecomponent recordings, Bull. Seismol. Soc. Am. 93, 1904-1912.

Center for Earthquake Research and Information

University of Memphis

3890 Central Avenue

Memphis, Tennessee 38152

(M.M.-D., H.R.D.)

Christian Albrechts University of Kiel

Institute of Geophysics

Otto-Hahn-Platz 1

D-24118 Kiel, Germany

(W.R., M.T., Y.D.)

Helmholtz Centre for Ocean Research (GEOMAR)

East Shore Campus

Wischhofstr 1-3

D-24148 Kiel, Germany

(I.G.A.)

Manuscript received 4 September 2012 